\title{
Free Radical Telomerization of Methacrylamide Using Bromotrichloromethane
}

\author{
Takao Kimura and Motome HamashimA \\ Department of Applied Chemistry, Faculty of Engineering, \\ Utsunomiya University, Ishii-cho, Utsunomiya 321, Japan
}

(Received June 17, 1988)

\begin{abstract}
The free radical telomerization of methacrylamide (MAA) with bromotrichloromethane (BTCM) as a chain transfer agent was carried out with varying temperature, molar ratio of BTCM to MAA, and solvent. The apparent overall activation energy for this system was calculated as $34 \mathrm{~kJ} \mathrm{~mol}^{-1}$. The growing radical with one repeating unit led to the formation of telomer accompanying normal chain transfer by bromine abstraction from BTCM, while growing radicals with two repeating units or more led to the formation of lactams through intramolecular cyclization of the resulting telomers with evolution of hydrogen bromide or selfcyclization accompanying chain transfer to produce a cyclic oligomer. The cis type was formed in preference to the trans one in a ratio of $3: 1-4: 1$ as diastereoisomeric lactams made from the growing radical with two repeating units.
\end{abstract}

KEY WORDS Free Radical Telomerization / Methacrylamide / Bromotrichloromethane / Telomerization Behavior / Telomer / Lactam / Chain Transfer /

Bromotrichloromethane (BTCM) is known as an effective telogen for the free radical telomerization of vinyl monomers by kinetic studies. ${ }^{1}$ In previous papers, ${ }^{2}$ we reported the free radical telomerization of thirteen kinds of methacrylates using BTCM as a telogen. The effects of the substituent in the ester group on the telomerization behavior and the reactivities of the resulting telomers were systematically studied. In particular, the lactones obtained as cyclic oligomers or their derivatives have been found useful as unique reactive oligomers. ${ }^{3}$ In expectation of the formation of lactams competing with the lactones, this work deals with the free radical telomerization of methacrylamide (MAA) using BTCM. In this paper, the effects of temperature, molar ratio of BTCM to MAA, and solvent on telomerization behavior are discussed, and a telomerization mechanism of MAA with BTCM is proposed.

\section{EXPERIMENTAL}

\section{Measurements}

Melting points were measured with a Yamato MP-21 melting point apparatus and are uncorrected. IR spectra were measured in $\mathrm{KBr}$ disks with a Hitachi 295 spectrophotometer. ${ }^{1} \mathrm{H}$ NMR spectra were determined with a JEOL JNM-C-60HL spectrometer $(60 \mathrm{MHz})$ using $\mathrm{Me}_{4} \mathrm{Si}$ as the internal standard. Mass spectra were recorded with a Hitachi M-80 spectrometer using the chemical ionization method at $20 \mathrm{eV}$ of ionization energy. All isotope peaks resulting from bromine and chlorine atoms were satisfactorily detected in the mass spectra. The isotope peaks corresponding only to ${ }^{79} \mathrm{Br}$ and ${ }^{35} \mathrm{Cl}$ are treated in this paper. Determination of organic halogen was carried out by semimicro higher alcoholmetallic sodium method. ${ }^{4}$ 


\section{Materials}

Commercial MAA was recrystallized from ethyl acetate before use. Commercial BTCM was purified by distillation under reduced pressure, and 2,2'-azobisisobutyronitrile (AIBN) by recrystallization from methanol. Commercial $N, N$-dimethylformamide (DMF) and ethyleneglycol (EG) were stored over molecular sieves 4A and distilled in vacuo before use. Commercial $\mathrm{N}$-methyl-2-pyrrolidone (NMP) was dried over calcium hydride and distilled in vacuo before use.

\section{Typical Procedure of Telomerization}

A DMF solution of MAA was placed in a three-necked round bottom flask equipped with a magnetic stirrer. BTCM was added to the solution, and the mixture was heated at a desired temperature with stirring under a nitrogen atmosphere. AIBN was then added to the solution to initiate the reaction. After a given time, under cooling below $20^{\circ} \mathrm{C}$, a small amount of hydroquinone was added to the solution to terminate the reaction.

\section{Typical After-treatment of Telomerization}

The unreacted BTCM and DMF were distilled off in vacuo. The residue was dissolved in an appropriate amount of $1: 1$ cyclohexaneethyl acetate at $60^{\circ} \mathrm{C}$, and filtered off. The insoluble white powder was further extracted with an appropriate amount of water at $60^{\circ} \mathrm{C}$ to remove ammonium bromide as the byproduct.

\section{Separation and Characterization of Products}

The filtrate was fractionated by column chromatography using silica gel (Wakogel C$300)$ as the packing material. The following products were succesively developed with $1: 1$ cyclohexane-ethyl acetate as the eluent.

2-Bromo-4,4,4-trichloro-2-methylbutanamide (1). Colorless needles (from cyclohexane); $\mathrm{mp}$ $101-102.5^{\circ} \mathrm{C}$; IR $1660 \mathrm{~cm}^{-1}(\mathrm{C}=\mathrm{O})$; MS $\mathrm{m} / \mathrm{z}$ (rel intensity) $282\left(\mathrm{QM}^{+}, 100\right), 245(25), 203$ (71), 165 (77), and 122 (44); Found: $\mathrm{Br}+\mathrm{Cl}$, $65.20 \%$. Calcd for $\mathrm{C}_{5} \mathrm{H}_{7} \mathrm{NOBrCl}_{3}: \mathrm{Br}+\mathrm{Cl}$, $65.73 \%$.

(2RS,4SR)-4-carbamoyl-2,4-dimethyl-2-<smiles>CC(C)C(C)(Br)C(N)(N)O</smiles>

1

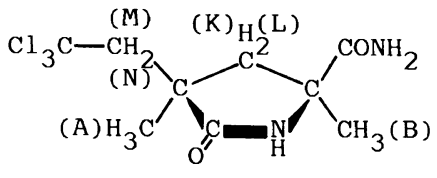

$2 \mathbf{a}$

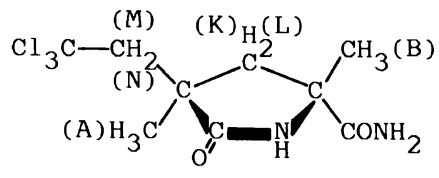

$2 \mathbf{b}$<smiles>CCC(C)(CC)C(N)=O</smiles> 
(2,2,2-trichloroethyl)-4-butanelactam (2a). Colorless grains (from ethyl acetate); $\mathrm{mp}$ 216-218 C; IR 1770 and $1700 \mathrm{~cm}^{-1}(\mathrm{C}=\mathrm{O})$; MS $m / z$ (rel intensity) $287\left(\mathrm{QM}^{+}, 100\right), 253$ (38), 242 (15), 157 (64), and 112 (14); Found: $\mathrm{Cl}, 37.17 \%$. Calcd for $\mathrm{C}_{9} \mathrm{H}_{13} \mathrm{~N}_{2} \mathrm{O}_{2} \mathrm{Cl}_{3}$ : $\mathrm{Cl}$, $36.98 \%$. The white powder unextracted with hot water was also collected as $\mathbf{2 a}$.

( $2 R S, 4 R S)$-4-carbamoyl-2,4-dimethyl-2(2,2,2-trichloroethyl)-4-butanelactam (2b). Colorless flakes (from carbon tetrachloride); $\mathrm{mp} 124.5-126^{\circ} \mathrm{C}$; IR 1770 and $1700 \mathrm{~cm}^{-1}$ $(\mathrm{C}=\mathrm{O}) ; \mathrm{MS} m / z$ (rel intensity) $287\left(\mathrm{QM}^{+}\right.$, 100), 253 (38), 242 (16), 157 (64), and 112 (12); Found: $\mathrm{Cl}, 37.26 \%$. Calcd for $\mathrm{C}_{9} \mathrm{H}_{13} \mathrm{~N}_{2} \mathrm{O}_{2} \mathrm{Cl}_{3}$ : $\mathrm{Cl}, 36.98 \%$.

(2SR,4SR)-4-carbamoyl-2-(2-carbamoyl-2methyl-4,4,4-trichlorobutyl )-2,4-dimethyl-4butanelactam (3a). Colorless crystals (from carbon tetrachloride); $\mathrm{mp} 121-124^{\circ} \mathrm{C}$; IR 1770, 1710, and $1660 \mathrm{~cm}^{-1}(\mathrm{C}=\mathrm{O}) ; \mathrm{MS} \mathrm{m} / z$ (rel intensity) $372\left(\mathrm{QM}^{+}, 1\right), 355$ (42), $320(26)$, 224 (100), 157 (30), and 114 (33); Found:
$\mathrm{Cl}, 28.82 \%$. Calcd for $\mathrm{C}_{13} \mathrm{H}_{20} \mathrm{~N}_{3} \mathrm{O}_{3} \mathrm{Cl}_{3}: \mathrm{Cl}$, $28.54 \%$.

\section{RESULTS AND DISCUSSION}

\section{Telomerization Behavior of Methacrylamide with $\mathrm{Cl}_{3} \mathrm{CBr}$}

Homogeneous telomerization was carried out in a solvent such as DMF because MAA is only slightly soluble in BTCM. The solution polymerization of MAA in only DMF gave MAA high polymer. Therefore, the chain transfer ability of DMF may be regarded as negligible in comparison with that of BTCM. The results of the solution telomerization of MAA with BTCM are summarized in Tables I, II, and III. As the reaction temperature rose as shown in Table I, the apparent rate of telomerization $\left(R_{\mathrm{p}}{ }^{\prime}\right)$ increased and the product distribution (MWD) shifted to a lower average degree of telomerization $(\bar{n})$. However, the content of $n$-mers $(n=1-2)$ was about $70 \mathrm{wt} \%$ of the overall one regardless of temperature.

Table I. Effect of temperature on the telomerization behavior of methacrylamide ${ }^{a}$

\begin{tabular}{|c|c|c|c|c|c|c|c|}
\hline \multirow{2}{*}{$\frac{\text { Temp }^{\mathrm{b}}}{{ }^{\mathrm{o}} \mathrm{C}}$} & \multirow{2}{*}{$\frac{R_{\mathrm{p}}^{\prime} \times 10^{5}}{\mathrm{moll}^{-1} \mathrm{~s}^{-1}}$} & \multicolumn{4}{|c|}{$\mathrm{MWD} / \mathrm{wt}^{\mathrm{o}} \%$} & \multicolumn{2}{|c|}{ Lactam $/ \%$} \\
\hline & & $n=1$ & $n=2$ & $n=3$ & Others & $2 \mathbf{a}$ & $2 b$ \\
\hline $30^{c}$ & 0.23 & 18 & 54 & 23 & 5 & 79 & 21 \\
\hline 50 & 1.08 & 40 & 31 & 10 & 19 & 82 & 18 \\
\hline 70 & 3.56 & 47 & 24 & 9 & 20 & 78 & 22 \\
\hline 90 & 6.60 & 49 & 23 & 9 & 19 & 76 & 24 \\
\hline
\end{tabular}

${ }^{\mathrm{a}}[\mathrm{MAA}]_{0}, 7.04 \times 10^{-2} \mathrm{~mol} ;[\mathrm{BTCM}]_{0}, 5.63 \times 10^{-1} \mathrm{~mol} ;[\mathrm{AIBN}]_{0}, 1.24 \times 10^{-3} \mathrm{~mol}$; $[\mathrm{DMF}]_{0}, 5.63 \times 10^{-1} \mathrm{~mol}$.

b Time, $72 \mathrm{~h}\left(30^{\circ} \mathrm{C}\right) ; 48 \mathrm{~h}\left(50^{\circ} \mathrm{C}\right) ; 16 \mathrm{~h}\left(70^{\circ} \mathrm{C}\right) ; 8 \mathrm{~h}\left(90^{\circ} \mathrm{C}\right)$.

c A mixture of [benzoyl peroxide $]_{0}, 0.89 \times 10^{-3} \mathrm{~mol}$ and $[N, N \text {-dimethylaniline }]_{0}, 0.89 \times 10^{-3}$ mol was used as redox initiator.

Table II. Effect of telogen concentration on the telomerization behavior of methacrylamide ${ }^{a}$

\begin{tabular}{|c|c|c|c|c|c|c|c|}
\hline \multirow{2}{*}{$\frac{[\mathrm{BTCM}]_{0}{ }^{\mathrm{b}}}{[\mathrm{MAA}]_{0}}$} & \multirow{2}{*}{$\frac{R_{\mathrm{p}}^{\prime} \times 10^{4}}{\mathrm{moll}^{-1} \mathrm{~s}^{-1}}$} & \multicolumn{4}{|c|}{$\mathrm{MWD} / \mathrm{wt}^{\circ} \%$} & \multicolumn{2}{|c|}{ Lactam $/ \%$} \\
\hline & & $n=1$ & $n=2$ & $n=3$ & Others & $2 \mathbf{a}$ & $\mathbf{2 b}$ \\
\hline 2 & 2.44 & 19 & 30 & 11 & 40 & 76 & 24 \\
\hline 8 & 0.66 & 49 & 23 & 9 & 19 & 76 & 24 \\
\hline
\end{tabular}

a $[\mathrm{MAA}]_{0}, 7.04 \times 10^{-2} \mathrm{~mol} ;[\mathrm{AIBN}]_{0}, 1.24 \times 10^{-3} \mathrm{~mol}$; temp, $90^{\circ} \mathrm{C}$; time, $8 \mathrm{~h}$.

b DMF was added in an amount equal to that of BTCM. 
Table III. Effect of solvent on the telomerization behavior of methacrylamide ${ }^{\text {a }}$

\begin{tabular}{|c|c|c|c|c|c|c|c|}
\hline \multirow{2}{*}{ Solvent ${ }^{b}$} & \multirow{2}{*}{$\frac{R_{\mathrm{p}}^{\prime} \times 10^{5}}{\mathrm{moll}^{-1} \mathrm{~s}^{-1}}$} & \multicolumn{4}{|c|}{$\mathrm{MWD} / \mathrm{wt} \%$} & \multicolumn{2}{|c|}{ Lactam $/ \%$} \\
\hline & & $n=1$ & $n=2$ & $n=3$ & Others & $\mathbf{2 a}$ & $2 \mathbf{b}$ \\
\hline DMF & 6.60 & 49 & 23 & 9 & 19 & 76 & 24 \\
\hline NMP & 5.93 & 42 & 25 & 2 & 31 & 80 & 20 \\
\hline $\mathrm{EG}$ & 4.06 & 32 & 16 & 24 & 28 & 79 & 21 \\
\hline
\end{tabular}

${ }^{\mathrm{a}}[\mathrm{MAA}]_{0}, 7.04 \times 10^{-2} \mathrm{~mol} ;[\mathrm{BTCM}]_{0}, 5.63 \times 10^{-1} \mathrm{~mol} ;[\mathrm{AIBN}]_{0}, 1.24 \times 10^{-3} \mathrm{~mol}$; temp, $90^{\circ} \mathrm{C}$; time, $8 \mathrm{~h}$.

b An amount equal to that of BTCM was added.

In addition, the apparent overall activation energy $\left(E_{\mathrm{a}}\right)$ for this system was calculated as $34 \mathrm{~kJ} \mathrm{~mol}^{-1}$. Since this value is apparently low relative to $E_{\mathrm{a}}=72 \mathrm{~kJ} \mathrm{~mol}^{-1}$ for methyl methacrylate-BTCM system, it is expected that an unique chain transfer reaction may result. As the molar ratio of BTCM to MAA increased as shown in Table II, the $R_{\mathrm{p}}{ }^{\prime}$ decreased and MWD shifted to a lower $\bar{n}$. The effect of the solvent on telomerization behavior shown in Table III was not so remarkable as those of temperature and BTCM concentration. But, in case of EG, the MWD shifted to a higher $\bar{n}$ centered in $n=3$ because of the immiscibility of BTCM in the MAA solution.

\section{Structure of Telomerization Products}

The ${ }^{1} \mathrm{H}$ NMR parameters of the resulting telomer and lactams are listed in Table IV. The orientation of adduct 1 corresponding to $n=1$ was confirmed by treatment with triethylamine (TEA). That is, the reaction of 1 with TEA gave the following elimination product in a reasonable yield: $\beta$-(trichloromethyl)methacrylamide, colorless plates (from cyclohexane) $\mathrm{mp} 98-99^{\circ} \mathrm{C}$; IR $1680(\mathrm{C}=\mathrm{O})$ and 1610 $\mathrm{cm}^{-1}(\mathrm{C}=\mathrm{C})$; MS $m / z 202\left(\mathrm{QM}^{+}\right) ;{ }^{1} \mathrm{H}$ NMR $\left(\mathrm{CDCl}_{3}\right) \delta 2.27\left(3 \mathrm{H}, \mathrm{d}, J=1.5 \mathrm{~Hz},-\mathrm{CH}_{3}\right)$, $6.29\left(2 \mathrm{H}, \mathrm{s},-\mathrm{CONH}_{2}\right)$, and $7.11 \mathrm{ppm}(1 \mathrm{H}, \mathrm{q}$, $J=1.5 \mathrm{~Hz},-\mathrm{CH}=)$. This elimination demonstrates that the trichloromethyl radical resulting from BTCM is selectively attached to the $\beta$-position of the double bond of MAA. On the other hand, all products correspond- ing to $n \geqq 2$ were obtained as cyclic oligomers. There were two diastereoisomers, 2a and $\mathbf{2 b}$, as lactams corresponding to $n=2$. As shown in Tables I, II, and III, the telomerizations of MAA gave $\mathbf{2 a}$ in preference to $\mathbf{2} \mathbf{b}$ in the ratio of $3: 1-4: 1$, regardless of the telomerization conditions. The configurations of both lactams were assigned on the basis of the ${ }^{1} \mathrm{H}$ NMR parameters of a couple of methylene protons $(\mathrm{K}, \mathrm{L})$ and $(\mathrm{M}, \mathrm{N})$. The methylene proton $(\mathrm{K}, \mathrm{L})$ of $\mathbf{2 a}$ showed an ambiguous $\mathrm{AB}$ pattern (doublet-doublet) in DMSO- $d_{6}$, whereas that of $\mathbf{2 b}$ showed a distinct $\mathrm{AB}$ pattern in both $\mathrm{CDCl}_{3}$ and DMSO- $d_{6}$ solvents. On the other hand, the methylene proton $(\mathrm{M}, \mathrm{N})$ of $\mathbf{2 a}$ showed a stronger $\mathrm{AB}$ pattern in DMSO- $d_{6}$ relative to that of $\mathbf{2 b}$. The magnitude of the magnetic unequivalence of these geminal methylene protons differs according to the configurations of $\mathbf{2} \mathbf{a}$ and $\mathbf{2 b}$. This assignment may be similarly explained by the difference in the magnetic environment based on the stable configurations of two diastereoisomeric lactones as discussed in the previous papers. ${ }^{2}$ Lactam 3a was isolated only as a cyclic oligomer corresponding to $n=3$. Furthermore, there were some carboxylic acids in other products. But the isolation and structural analysis of those were not successfully carried out.

\section{Stoichiometric Relation between Lactams and Ammonium Bromide as By-Product}

The lactams were always accompanied with the formation of ammonium bromide. Table $\mathrm{V}$ 
Table IV. ${ }^{1} \mathrm{H}$ NMR parameters of the isolated products

\begin{tabular}{|c|c|c|c|c|}
\hline \multirow{2}{*}{ Product } & \multirow{2}{*}{ Proton } & \multirow{2}{*}{ Symbol } & \multicolumn{2}{|c|}{ Chemical shift $\delta / \mathrm{ppm}$} \\
\hline & & & $\mathrm{CDCl}_{3}{ }^{\mathrm{a}}$ & DMSO- $d_{6}$ \\
\hline 1 & $\begin{array}{l}-\mathrm{CH}_{3} \\
-\mathrm{CH}_{2-}^{-}\end{array}$ & $\stackrel{\mathrm{A}}{\mathrm{M}, \mathrm{N}}$ & $\begin{array}{l}2.17 \\
3.79\end{array}$ & $\begin{array}{c}2.13 \\
4.263 .63 \\
{[37.8]^{\mathrm{b}}} \\
(15.6)^{\mathrm{c}}\end{array}$ \\
\hline $2 \mathbf{a}$ & $\begin{array}{l}-\mathrm{CH}_{3} \\
-\mathrm{CH}_{3} \\
-\mathrm{CH}_{2-}^{-} \\
-\mathrm{CH}_{2-}\end{array}$ & $\begin{array}{c}\text { A } \\
\text { B } \\
\mathrm{K}, \mathrm{L}\end{array}$ & - & $\begin{array}{c}1.55 \\
1.26 \\
2.842 .58 \\
{[15.6]} \\
(13.2) \\
3.503 .15 \\
{[21.0]} \\
(16.2)\end{array}$ \\
\hline $\mathbf{2 b}$ & $\begin{array}{l}-\mathrm{CH}_{3} \\
-\mathrm{CH}_{3} \\
-\mathrm{CH}_{2}- \\
-\mathrm{CH}_{2}-\end{array}$ & $\begin{array}{c}\text { A } \\
\text { B } \\
\mathrm{K}, \mathrm{L}\end{array}$ & $\begin{array}{c}1.74 \\
1.54 \\
3.442 .24 \\
{[72.0]} \\
(15.0) \\
3.433 .09 \\
{[20.4]} \\
(16.2)\end{array}$ & $\begin{array}{c}1.58 \\
1.44 \\
3.192 .13 \\
{[63.6]} \\
(14.4) \\
3.393 .09 \\
{[18.0]} \\
(15.6)\end{array}$ \\
\hline $\mathbf{3 a}$ & $\begin{array}{l}-\mathrm{CH}_{3} \\
-\mathrm{CH}_{3} \\
-\mathrm{CH}_{3} \\
-\mathrm{CH}_{2-}- \\
-\mathrm{CH}_{2}-\end{array}$ & $\begin{array}{c}\text { A } \\
\text { B } \\
\text { C } \\
\text { I, J } \\
\text { K, L }\end{array}$ & $\begin{array}{l}- \\
- \\
-\end{array}$ & $\begin{array}{c}1.46 \\
1.46 \\
1.17 \\
1.83 \\
2.58 \quad 2.19 \\
{[23.4]} \\
(14.4) \\
3.76 \quad 2.85 \\
{[54.6]} \\
(16.2)\end{array}$ \\
\hline
\end{tabular}

a Measurement of 2a and 3a was not possible.

b [ ]: Difference in chemical shifts $\Delta \delta$ in $\mathrm{Hz}$.

c ( ): Coupling const $J$ in $\mathrm{Hz}$.

Table V. Stoichiometric relation between lactams and ammonium bromide

\begin{tabular}{|c|c|c|}
\hline Temp $^{a}$ & Lactams & $\mathrm{NH}_{4} \mathrm{Br}$ \\
\hline${ }^{\circ} \mathrm{C}$ & mmol & $\mathrm{mmol}$ \\
\hline 30 & 4 & 3 \\
\hline 50 & 20 & 23 \\
\hline 70 & 18 & 17 \\
\hline 90 & 16 & 17 \\
\hline
\end{tabular}

${ }^{\text {a }}$ See Table I. i) Initiator $\rightarrow 2 R$.

ii) $\mathrm{R} \cdot+\mathrm{Cl}_{3} \mathrm{CBr} \rightarrow \mathrm{RBr}+\mathrm{Cl}_{3} \mathrm{C}$.

iii) $\mathrm{Cl}_{3} \mathrm{C} \cdot+\mathrm{MAA} \rightarrow \mathrm{Cl}_{3} \mathrm{C}-\mathrm{CH}_{2}-\stackrel{\mathrm{CONH}_{2}}{\mathrm{CH}_{3}}$

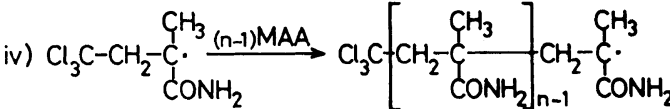

$\left(\equiv P_{n} \cdot\right)$

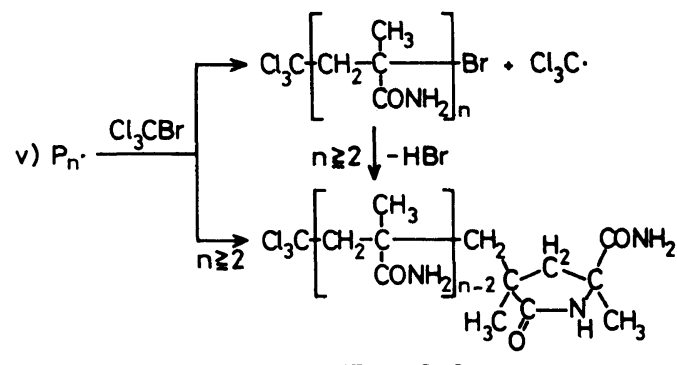

- $\mathrm{HBr}+\mathrm{Cl}_{3} \mathrm{C}$.

vi) $\left(-\mathrm{CONH}_{2}+\mathrm{H}_{2} \mathrm{O} \longrightarrow-\mathrm{COOH}+\mathrm{NH}_{3}\right)$

$\mathrm{HBr}+\mathrm{NH}_{3} \longrightarrow \mathrm{NH}_{4} \mathrm{Br}$

Scheme 1. Mechanism of telomerization

shows the stoichiometric relation between lactams and ammonium bromide as the byproduct. The ammonium bromide existed in nearly an equimolar amount with the lactams, regardless of temperature, and is an important by-product for the mechanistic consideration of the formation of lactams.

\section{Mechanism of the Telomerization of Methac- rylamide with $\mathrm{Cl}_{3} \mathrm{CBr}$}

The free radical telomerization of MAA with BTCM is considered to proceed as shown in Scheme 1. The growing radical $\left(P_{n} \cdot\right)$ results from a sequence of elementary reactions i) iv). The resulting $P_{n}$. induces a chain transfer reaction against BTCM as expressed in eq v). The $P_{n} \cdot(n=1)$ leads to telomer 1 , namely $1: 1$ MAA : BTCM adduct accompanying normal chain transfer by bromine abstraction from BTCM. On the other hand, the $P_{n} \cdot(n \geqq 2)$ leads to only lactams. The formation of lactams is expected to proceed by one of the 
following routes. One route is the intramolecular cyclization of the resulting telomers $(n \geqq 2)$, with the evolution of hydrogen bromide, and the other one is the self-cyclization of $P_{n} \cdot(n \geqq 2)$, with hydrogen liberation from the carbamoyl group present in the penultimate unit. The released hydrogen atom reacts with BTCM, and hydrogen bromide and the trichloromethyl radical are simultaneously produced. Then the resulting hydrogen bromide is apt to induce the catalytic hydrolysis of amides into carboxylic acids and ammonia. As expressed in eq vi), the resulting ammonia reacts rapidly with the hydrogen bromide and is finally caught as ammonium bromide. Furthermore, the resulting trichloromethyl radicals via eq v) revert to eq iii) and cause MAA to reinitiate efficiently.
Acknowledgments. The authors are grateful to Miss N. Miyazaki and Mr. K. Shionuma for their assistance in this experiment.

\section{REFERENCES}

1. C. M. Starks, "Free Radical Telomerization," Academic Press, Inc., New York, N. Y., 1974, Chapter 6.

2. T. Kimura, T. Kodaira, and M. Hamashima, Polym. J., 15, 293 (1983); T. Kimura and M. Hamashima, ibid., 18, 21 (1986); T. Kimura, I. Nakanishi, and M. Hamashima, ibid., 18, 689 (1986); T. Kimura, H. Tasaka, and M. Hamashima, ibid., 19, 305 (1987); T. Kimura, T. Yoshimura, H. Morimoto, and M. Hamashima, ibid., 19, 1165 (1987); T. Kimura and M. Hamashima, ibid., 20, 45 (1988).

3. T. Kimura, M. Kishimoto, and M. Hamashima, Polym. Prepr., Jpn., 34, 255 (1985).

4. Y. Yano, K. Izawa, H. Iwata, K. Ichikawa, and W. Kimura, Bunseki Kagaku, 10, 1358 (1961). 